$10-1-2004$

\title{
Anatomy of a Youngster's Suicide: Whose Problem is it?
}

Robert C. Grosz

Nova Southeastern University, rgrosz@nova.edu

Follow this and additional works at: https://nsuworks.nova.edu/ijahsp

Part of the Medicine and Health Sciences Commons

\section{Recommended Citation}

Grosz RC. Anatomy of a Youngster's Suicide: Whose Problem is it?. The Internet Journal of Allied Health Sciences and Practice. 2004 Oct 01;2(4), Article 3.

This Commentary is brought to you for free and open access by the College of Health Care Sciences at NSUWorks. It has been accepted for inclusion in Internet Journal of Allied Health Sciences and Practice by an authorized editor of NSUWorks. For more information, please contact nsuworks@nova.edu. 


\section{Anatomy of a Youngster's Suicide: Whose Problem is it?}




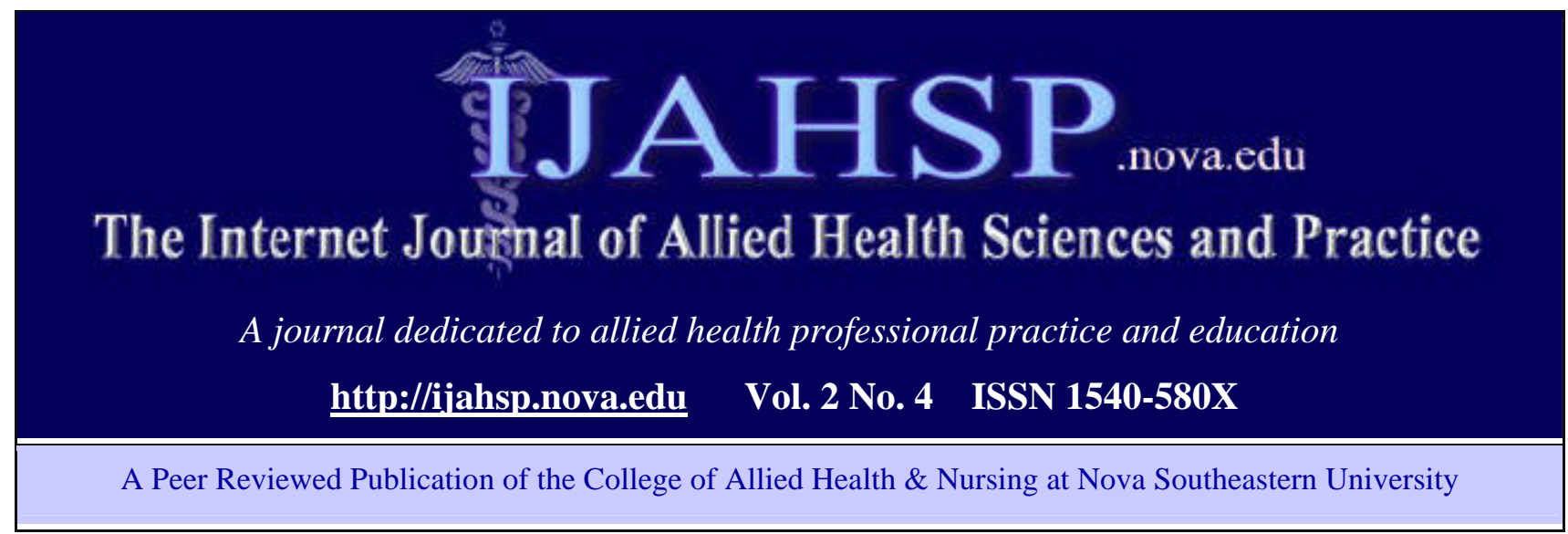

Commentary

\title{
The Anatomy of a Youngster's Suicide: Whose Problem Is It?
}

\author{
Robert C. Grosz, EdD \\ Professor \\ Physician Assistant Program \\ Nova Southeastern University \\ College of Allied Health and Nursing
}

\section{Citation:}

Grosz, R.; The anatomy of a youngster's suicide. The Internet Journal of Allied Health Sciences and Practice. Commentary. October 2004. Volume 2 Number 4.

Youngsters wanting to take their own lives: A few generations ago this was unthinkable and indeed unbelievable. What could drive a youngster to that point? What problems could he/she possibly have? They hadn't even entered the "real world" yet. Did youngsters have the responsibilities that adults have? The consensus of thinking was, "of course not." After all, youngsters didn't have to worry about getting jobs or being laid off jobs. They didn't concern themselves with paying bills, being responsible for youngsters, making life decisions such as marrying, having a child, buying a house, buying a car, where to get the mortgage, saving for retirement or college, maintaining the health of a family, electing the right people, etc. To the average adult, these were the only problems that were worth getting concerned over.

All the average youngster had to contend with was basic day-by-day needs such as going to school or getting along with someone else and even that was not a chore. If you don't 
like the other kid, don't work it out just play with someone else! Other daily needs were if the child became ill, a parent (and/or doctor) would take care of it. Basic necessities were provided (food, clothing and shelter). As a matter of fact, we generally did just that. We looked upon youngsters as the "average youngster," because they had not yet experienced, participated in, concerned themselves with, or been exposed to what the average adult considered to be "real life decision-making." Indeed it was our (adults) mature responsibility to "protect and shield" youngsters from these "problems."

In the movies, it was almost an unwritten code that virtually any movie that included anyone below the age of 18 should have at least one scene whereby the youngster was shown being tucked in and/or in a peaceful sleep without a care in the world as the admiring parent looked on. Even the early movies (silent and early talkies) that revolved around children growing up in rags, poverty and in the streets, had the scenes in which the parent or guardian would tuck in the peaceful face of the child who went to sleep immediately, while being told that there was nothing to worry about.

It seems that it was the objective of the "real world" to keep children in a "world of fantasy" and thus viewed them as such.

To better understand the anatomy of a youngster's attempt at suicide we have to explore the stages of development of the youngster. This usually entails three basic phases:

The first phase is the Search for Identity which builds up under the ages of 15-17 when the youngster is looking for attention, asking "who am I" and hoping that someone "listens to me...I have something to say." Around 17 or so the youngster then starts to consider not just "who am I" but also "what shall/will I do/be?" In sorting these concerns out, the youngster usually runs into parental conflict (regimentation, restrictions, scheduling, all without input. When there is an attempt to have input, the input is generally rejected and decisions are made for them so we add some frustration to this phase of life. Add to this conflict some values confusion. Often parents or teachers demand one thing and then act in contradiction. In addition, feelings of guilt and confusion over loyalties and friendships enter the mix. The youngster often will resort to doing things that he/she knows should not be done and then experience some sense of guilt over their actions. In these early years, often beginning with early social experience and development, questions arise regarding who to be friendly with and for what reasons, how to decide, just how far should loyalty go, how can changes be made, and who are the role models that influence friendships and loyalties.

These are all forces that help to shape the Self-Concept or Image (meaning how the youngster feels about him/herself) and the Self-Esteem or Worth (meaning how approving of their own behavior are they). For example, the youngster perceives of himself as being honest, yet he cheats on an exam and then is not happy with how he behaved. She believes that she is truthful yet lies when asked if she has been smoking, and thus is unhappy with how she behaved (self esteem). In addition to the aforementioned forces, other influences on image and esteem are their own physical images of themselves and acceptances or rejections into selected environments or groups. If they experience 
difficulties and enter into some degree of "crisis identity," they frequently set the stage for the second phase of the Anatomy of a Suicide, which is Depression.

Depression in adults is often represented by slightly different behavior as opposed to depression in a youngster. The adult usually shows clinical depression with withdrawal, retreat, isolation in addition to other signs. The youngster frequently demonstrates depression with periods of irritability, agitation and/or violence. Complications usually include cognitive difficulties demonstrated through academic underachieving, poor judgment, and social problems. The major underlying factor being that owing to the "lack of years and exposure" as opposed to an adult, the chances are the youngster will not have the coping strategies or experiences that adults have developed. When youngsters become clinically depressed they generally experience behavioral complications such as anxiety (in the form fears), personality problems ( such as guilt), dysmorphia ( a dissatisfaction with the body such as weight), paranoia (in form of distrust), bipolar behavior (like mood swings), and often borderline behavior ( such as unstable relationships).

As we uncover more of the "anatomy of preadolescent or adolescent suicide," we learn more of the risks that make one more of a candidate. Such as the probability that there is a genetic factor that might make one more vulnerable, or a biological factor such as a chemical imbalance that might even be genetic, or a social factor that might revolve around the family environmental exposure, or a peer factor that involves a variety of influences such as rejection. In analyzing any of these, one can see that it is possible that while we might not be able to make any of these factors or risks disappear, it might be possible to learn how to cope with these influences. Without assistance or some tailor made-age related, educational process or exposure, how would we expect a 7 year old, or 9 or 11 year old, or a teenager to have the capability to cope with these problems? Add to this mix the realism that youngsters today are becoming more and more "isolated" as they spend more and more time in front of screens (TV and/or computer).

When the stresses mount, the adult is more apt to become conscious of his/her situation, recognize frustration, and be aware that there could be outlets that might help to relieve the pressures. A clinical state of depression in anyone is a result of specific, individual factors that may or may not be identified and the inability to find adequate coping.

Without understanding the concept of coping or the experience of seeking out the potential coping mechanisms that might be at the youngster's disposal, the last resort that can be a coping mechanism could be suicide. Suicide represents a coping mechanism that could relieve the youngster of the burdens that cannot be dealt with, and is totally within his/her own control.

If we can see this process as the "anatomy of suicide" for a youngster, and recognize that these pressures can be identified and do exist at such young ages, then perhaps we should be focusing on developing some formal, age-specific, educational processes that can be delivered in a classroom setting at the lower grade levels. Something such as role- 
playing games that shows how a 7 year old decides under what circumstances to go, and to which person and how to ask for what type of help.

Probably the most important step to be taken is that of recognizing that the ages of 5 or 6 to 17 or 18 are not immune to monumental, daily problems that have a profound effect on daily behavior. To some children choosing which dessert they want may be as difficult as some adults choosing which stock to buy, or a college student choosing which career path to follow. To each, the decision-making process weighs heavily and might be equally profound in consequences. To each his/her decision is most important and of an immediate nature. The next most important element in dealing with preparing a youngster to cope is recognizing who are the most influential individuals to be in a position to help children learn how to cope. The parent, a relative, the teacher, the coach the cleric, and the friend are some of the logical possibilities, and an educational process can be developed to educate children on how they might be a in a position to utilize these outlets when under pressure. A better understanding of what pressures are can be another educational objective. Again, these educational processes could be age-specific.

The bottom line is, shouldn't we be able to bring together the advanced resources that we have today and come up with the adequate processes with which we can expose youngsters to acquire adequate coping mechanisms with which to try to relieve ever mounting stresses on younger and younger minds so as to avoid relying on the ultimate coping mechanism represented by the act of suicide? 